\section{Birth Order Effects in Autism}

Tychele N. Turner

University of Washington, Seattle, WA, USA

\section{Synonyms}

Birth order; Birth rank effect

\section{Definition}

Birth order relates to the order in which a child is born to a set of parents and birth order effects refer to differences seen between individuals that are not of the same birth order. In autism, birth order effects have been identified in a few studies. One type of birth order effect that has been observed and replicated is a lower nonverbal IQ score in the second child with autism in the family (Lord 1992; Spiker et al. 2001). Another study found that there was an effect of birth order on multiple aspects of autism including repetitive behaviors, phrase speech, social communication, and nonverbal communication (Reichenberg et al. 2007). Finally, in a more recent study general birth order effects were seen where middle births in multiplex families and later births in simplex families were more likely to develop autism (Turner et al. 2011). There are a number of potential reasons for birth order effects, and these include demographic factors such as stoppage in a family after the first child with autism is born, as well as biological factors including paternal age effects, maternal age effects, maternal-fetal genotype incompatibilities, and potential epigenetic effects. The discovery of birth order effects can help guide researchers in their examination of potential risk factors for autism.

\section{References and Reading}

Lord, C. (1992). Birth order effects on nonverbal IQ in families with multiple incidence of autism or pervasive developmental disorder. Journal of Autism and Developmental Disorders, 22(4), 663-666.

Reichenberg, A., Smith, C., Schmeidler, J., \& Silverman, J. M. (2007). Birth order effects on autism symptom domains. Psychiatry Research, 150(2), 199-204. https://doi.org/10.1016/j.psychres.2004.09.012.

Spiker, D., Lotspeich, L. J., Dimiceli, S., Szatmari, P., Myers, R. M., \& Risch, N. (2001). Birth order effects on nonverbal IQ scores in autism multiplex families. Journal of Autism and Developmental Disorders, 31(5), 449-460.

Turner, T., Pihur, V., \& Chakravarti, A. (2011). Quantifying and modeling birth order effects in autism. PLoS One, 6(10), e26418. https://doi.org/10.1371/journal. pone. 0026418 . 